\title{
Pina Soy: A New Drink with Desirable Organoleptic Characteristics
}

\author{
PA Ebabhamiegbebho ${ }^{\mathrm{a}}, \mathrm{OH}$ Momodu $^{\mathrm{a}}$ and $*$ SE Evivie ${ }^{\mathrm{a}, \mathrm{b}}$ \\ ${ }^{a}$ Food Science and Human Nutrition Unit, Department of Animal Science, Faculty of Agriculture, University of \\ Benin, PMB 1154, Benin City, Edo State, Nigeria \\ ${ }^{b}$ Key Laboratory of Dairy Science, Ministry of Education (KLDS-MOE), College of Food Science, Northeast \\ Agricultural University, Harbin 150030, PR China \\ Corresponding Author's Email: besta_intercom@yahoo.com, smith.evivie@uniben.edu
}

\begin{abstract}
This study was carried out to formulate a drink "Pina soy" by blending different proportions of soybean milk and pineapple juice with the aim of firstly suppressing the "beany flavor" associated with soymilk. The blends were prepared using different proportions of pineapple juice and soya milk in the ratio 20/80, 40/60, $50 / 50,60 / 40,80 / 20$ in addition to two controls which were $100 \%$ pineapple and 100\% soy. The different blends were formulated, homogenized, packaged and accessed for organoleptic (sensory) properties. Results showed that in terms of taste, $100 \%$ pineapple with a mean value of 4.50 and $80 / 20 \%$ pineapple/soy with a mean value of 4.45 were the most preferred while the least preferred was the 100\% soy with mean value of 2.25 . In terms of aroma and thickness the most preferred samples were 100\% pineapple with mean scores of 4.15 and 4.50 and $80 / 20 \%$ pineapple/soy with mean score of 4.00 and 4.25 , respectively. Mean scores obtained for colour showed that the same blends were the most preferred sample while the least preferred sample was 20/80\% pineapple/soy with mean score of 3.45. On the overall acceptability, "Pina soy" drink prepared from $80 \%$ pineapple juice blended in soy milk was the most acceptable blend (4.35) while the 20/80\% pineapple/soy was the least accepted (2.50). Further acceptability studies using older people as panelists is recommended.
\end{abstract}

Keywords: Juice, Pineapple, Processing, Sensory evaluation, Soybeans

\section{Introduction}

The primary role of any diet is to provide sufficient nutrients to meet the body requirements of an individual. Research has shifted to the identification of biologically active components in food which improve the physical and mental wellbeing of an individual and reduces the risk of diseases as well. Many traditional food products including fruits, vegetables, soy, whole grain and milk have been shown to have potential health benefits and consumers acknowledge that food play an indispensible role in health recovery and maintenance (Mollet and Rowland, 2002). Most of the world's nutrition related diseases including birth defects, mental and physical retardation, weakened immune systems, blindness and at times death are caused by the consumption of diets lacking in vitamins and minerals (micronutrients). Fruits are full of these essential vitamins and minerals hence should be consumed regularly. Fruits consumption is beneficial to health and contributes to the prevention of degenerative processes, particularly in lowering the incidence and mortality rate of cancer and cardiovascular diseases (Rapisarada et al., 1999).

Pineapple (Ananas comosus) has long been one of the most popular of the non-citrus tropical and subtropical fruits, largely because of its attractive flavor and refreshing sugar-acid balance (Bartolome., et al., 1995). Pineapple juice is largely consumed around the world, mostly in the form of single strength, reconstituted or concentrated and in the blend composition to obtain new flavors in beverages and other products (De Carvalho et al., 2008). Pineapples are very rich in fibre which is effective for curing constipation as well as ease bowel movement; it is low in cholesterol and fat. Vitamin $\mathrm{C}$ which is a natural antioxidant present in pineapple juice and helps to boost the immune system; prevent gum disease thus keeping the teeth healthy. Manganese present in pineapple juice is an effective mineral for the growth of healthy bones and tissues. Bromelian which is also present in pineapple juice has significant anti inflammatory effect, aids in menstrual disorder and sore throat relief (Onuekwe, 2012)

Soybean (Glycine max) belongs to the family of Leguminoseae. It is about the most utilized legume as well as the most well researched and health-promoting food material in the world today (William and Akiko, 2000, Akubor et al. 2003). Soymilk is a fine, off-white or creamy emulsion, which resembles cow milk in both appearance and consistency. Soymilk has low cholesterol and lactose levels, ability to reduce bone loss and menopausal symptoms, prevention and reduction of heart disease and certain cancers (Mbajiuka et al., 2014). The incease in the rate of soymilk consumption has encouraged low-scale production of the milk under household conditions with little or no regard to quality control measures. Soymilk has poor consumer acceptability, principally because of the "beany flavor" and flatulence inducing oligosaccharides such as starchyose and 
raffinose (Buono et al, 1990; Osundahunsi et al, 2007). Approaches towards removal of the "beany flavor" include heat inactivation of the lipoxygenase enzyme in whole dry bean during grinding process, starting with defatted material. Alternatively, this can be done by masking the bitterness and "off flavor" with sweetening and flavorings. Presently, some fruit juice blended soy beverages are available in the market (Rostango et al., 2007). Some studies have also shown that pineapple flavors are effective in suppressing the beany flavor, thus resulting in more acceptable products (Hazen, 2007). Besides flavoring the milk, pineapple is an important source of essential nutrients like minerals and vitamins, especially vitamin C. A possible blend of soymilk and pineapple juice would yield a composite drink which is rich in nutrient and can suppress the "beany" flavor of soymilk. It can also serve as a "quick fixer" drink for malnourished children and adults who are convalescing. The main objective of this study was to develop a consumer acceptable composite vegetable milk drink using blends of pineapple juice and soymilk The specific objectives were to (i) process soy milk and pineapple into juice, (ii) formulate different levels of the soy milk and pineapple blend, (iii) conduct a consumer sensory evaluation of the product, and (iv) determine the levels of inclusion at which the product will be most acceptable to the consumers.

\section{Site of Experiment}

\section{Materials And Methods}

The experiment was carried out in the Faculty of Agriculture Laboratory, University of Benin, Benin City, Edo state, Nigeria.

\section{Production of pineapple juice}

Freshly harvested, wholesome pineapples were purchased from a reputable pineapple vendor at Ogbemudia Street, Evobomore quarters, Benin City, Edo State, Nigeria, The pineapples were washed, peeled and diced into irregular shapes with a knife for easy blending. The blended pineapple was sieved with a cheesed cloth and the juice obtained pasteurized at $72^{\circ} \mathrm{C}$ for $15 \mathrm{~min}$ before packaging. The flow chart for production of the pineapple juice is shown in Fig. 1.

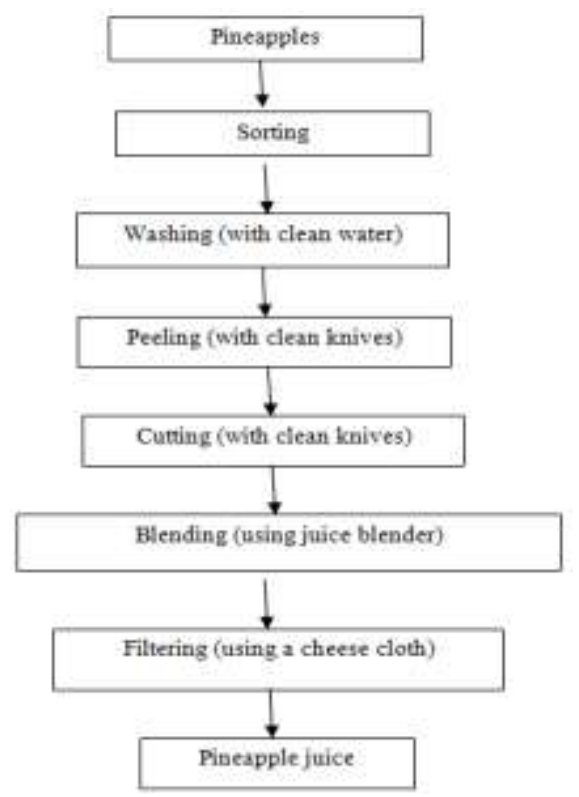

Source: Akinosun (2010)

Fig 1: Unit operation for the production of pineapple juice

\section{Production of soymilk}

Soymilk for this study was prepared as described by Igene and Ebabhamiegbebho (2009). Clean soybeans were also purchased from new Benin market and then processed into soymilk. The processing of the soy beans into milk was carried out in stages The first stage involved soaking the already sorted beans in about $1 \%$ sodium hydrogen carbonate $\left(\mathrm{NaHCO}_{3}\right)$ solution for $16 \mathrm{~h}$ in order to soften the soybean seeds. The soaked soybeans was boiled for about $20 \mathrm{~min}$. Immediately after boiling, the water was drained off and the beans dehulled manually, washed and blended withwater at $30^{\circ} \mathrm{C}$ to form slurry. The slurry was diluted with about 5 litres of water which was boiled to obtain homogenous slurry and thereafter filtered to have the soymilk. The soymilk was then pasteurized at $70^{\circ} \mathrm{C}$ for $10 \mathrm{~min}$ with stirred continuously to prevent the product from burning. Thereafter the 
milk was filled hot into already sterilized bottles, cooled and then refrigerated. The flowchart for production of soymilk is presented in Figure 2.

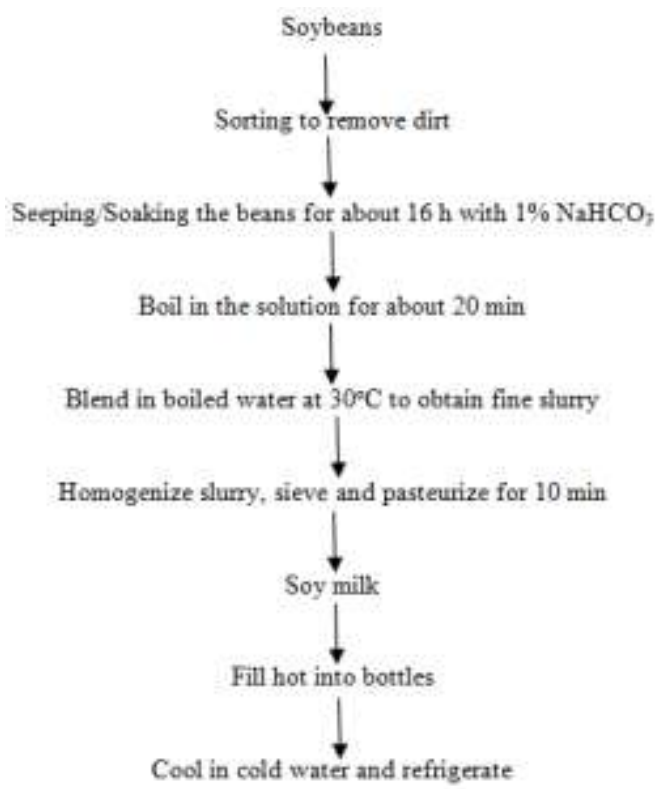

Fig 2: Unit operation for the processing of soy milk

Source: Igene and Ebabhamiegbebho, (2009)

\section{Formulation of pineapple soy blend "Pina soy"}

'Pina soy' was formulated by blending different proportions of pineapple juice and soymilk as follows; two controls. These were; (i) $100 \%$ soy (control), (ii) $100 \%$ pineapple (control) (iii) $50 / 50 \%$ pineapple / soy, (iv) 60 / 40\% pineapple / soy, (v) 40 / 60\% pineapple / soy, (v) 80 / 20\% pineapple / soy, and (vi) $20 / 80 \%$ pineapple / soy. No additive was added.

\section{Organoleptic (Sensory) Evaluation}

The samples were coded (using $111,222,333,444,555,666,777$ ) and presented to a taste panel of 20 judges to access the sensory attributes in terms of taste, color, aroma, thickness/ mouth feel and overall acceptance, using a 5-point Hedonic scale having 5 (like extremely) as the highest score and 1 (dislike extremely) as the lowest score. Water was presented to the judges rinse their mouth properly in between samples testing.

\section{Statistical Analysis}

The data obtained were analyzed using SPSS (Version 16.0) statistical software package and the significant treatment means were separated by Duncan Multiple Range test (Alika, 2006).

\section{Results And Discussion}

The results obtained from the study showed that $4.5 \mathrm{~kg}$ of soy beans that was used gave a yield of 6.2 $\mathrm{kg}$ of soy milk while $6.7 \mathrm{~kg}$ of pineapple yielded $5.4 \mathrm{~kg}$ of pineapple juice. In the sensory evaluation of the product "Pina soy", the taste scores showed that $100 \%$ pineapple and $80 / 20 \%$ pineapple/soy were not significantly different $(\mathrm{p}>0.05)$, but were significantly higher $(\mathrm{p}<0.05)$ than scores for other samples. It was also observed that taste score for the $100 \%$ soy control was significantly lower than that of the $40 / 60 \%$ pineapple/soy blend. There was no significant difference ( $p>0.05$ ) between 50/50\% pineapple/soy (3.20) and 60/40\% pineapple/soy (3.70) (Table 1). The high values recorded for $100 \%$ pineapple and $80 / 20 \%$ pineapple/soy may be attributed to the higher percentage of pineapple which added to the sweetness and were most acceptable probably because the taste panel consisted mainly of young persons (students) who would prefer high sugar products rather than low sugar products. The results may have been different if the samples were administered among adults. Similar results have been observed in a study carried out by Kale et al. (2012) where soymilk and orange juice were blended in different proportions into a drink in a bid to suppress the" beany flavor" of soymilk. The different blends were served to a group of panelist and it was observed that the drink with $70 \%$ orange was most accepted in terms of taste. There may be need to carry out further acceptability studies including panelists from different age brackets in order to further validate the assertions reported in this study.

In terms of aroma, $100 \%$ pineapple (4.15) 80/20\% pineapple/soy (4.00), 50/50\% pineapple/soy (3.45) and 60/40\% pineapple/soy (3.60) were not significantly different ( $\mathrm{p}>0.05)$ from each other but significantly 
higher $(\mathrm{p}<0.05)$ than the other samples. The most preferred in terms of aroma was the $100 \%$ pineapple with mean score of 4.15, while "Pina soy" with 20\% pineapple was least accepted with mean score of 2.95 (Table 1). Again, the low acceptability of this product could also be attributed to the low percentage of pineapple in the formulation which would have impacted a good aroma that will be appealing to the consumer and also the "beany flavor" of the soy milk could not be suppressed due to the high percentage of soy in that formulation. Soybeans confers what is generally termed "beany flavor" which has been shown in earlier studies (Buono et al., 1990; Osundahunsi et al., 2007) to be a major inhibition to the consumption has earlier reported that this is the major inhibition to the consumption of soy products. The nutritional and health benefits of soybeans cannot however be ruled out (Messina, 1999, 2010; Zhou, 2004) and so further studies are required to explore the lowering of this flavor and at the same time, retaining high nutritional quality and acceptability among consumers.

Regarding thickness scores for the blends, there was no significant difference ( $p>0.05$ ) among $100 \%$ soy, $40 / 60 \%$ pineapple/soy, $50 / 50 \%$ pineapple/soy and $20 / 80 \%$ pineapple/soy, while $100 \%$ pineapple with mean score of $4.05,60 / 40 \%$ pineapple/soy with mean score of 3.70 and $80 / 20 \%$ pineapple/soy with mean score of 4.25 were also not significantly different $(\mathrm{p}>0.05)$ from one another. The most preferred "Pina soy" drink in terms of thickness was the $80 / 20 \%$ pineapple/soy, while the least preferred samples were the $100 \%$ soy and $20 / 80 \%$ pineapple/soy having same mean score of 3.00 .

The highest score obtained for color was observed in $100 \%$ pineapple with a mean score of 4.45 and was therefore the most preferred while 50/50\% pineapple/soy had the lowest mean score of 3.30 and was the least preferred. There was also no significant difference ( $p>0.05)$ among $100 \%$ soy, $100 \%$ pineapple, $60 / 40 \%$ pineapple/soy and 80/20\% pineapple/soy having mean scores of 3.75, 4.45, 3.90 and 4.35 respectively. The high preference may also be as result of higher percentage of pineapple in those blends and the panelists who consisted mainly of students may be naturally attracted to the sweet aroma and bright color of the pineapple. Older people may have preferred "Pina soy" drink with higher percentage of soy because at their age they prefer drinks with lesser amount of sugar. Earlier reports have shown that color is an important factor in terms of how food is displayed and sold, and thus it is an indices used in quality control. Color is also added to foods to stimulate the appetite (Dias et al., 2012; Boles and Pegg, 2005) as well as stimulating physical and physiological reactions (Crepaldi, 2006).

In terms of overall acceptability, the $80 / 20 \%$ pineapple/ soy blend was the most acceptable with a mean score of 4.35 which was not significantly different $(\mathrm{P}>0.05)$ from the $100 \%$ pineapple control which had a mean acceptability score of 4.40 . On the other hand, the $20 / 80 \%$ pineapple/soy blend was the least acceptable sample by panelists with an average score of 2.50 . This score was not significantly different from that of the $100 \%$ soy control used in this study (2.65). (Table 1, Fig 4). This result showed that the sensory properties of "Pina soy" decreased with increase amount of soymilk present in the blends, thus suggesting an inverse relationship between these two parameters which is is similar to the findings of Rostango et al., (2007). The results from this study were also consistent with those obtained from the research work on orange soy beverage formulated by Kale et al. (2012). These researchers also showed that in terms of taste, aroma, color, mouth feel and overall acceptability, the panelist preferred the blend with $80 \%$ orange juice, while the blend with $10 \%$ orange juice was least accepted. Similar research in a work by Villegas (2009) also showed that the panelist preferred soymilk with pineapple flavours to plain soy milk. The low acceptability of "Pina soy" with high percentage of soymilk substitution may also be attributed to the fact that the samples were served in their natural state (that is without any form of flavor). In all these, there is an indication that the panelists were still not accustomed to soymilk, probably because of its "beany flavor". Although the presence of soymilk in combination with pineapple juice may have increased the nutritional quality of the "Pina soy" drink, the taste, flavor, aroma and color of soymilk were still not acceptable to the consumers of the product. We thus hypothesize that the resultant blends still had some undesirable sensory qualities that made them less acceptable to the consumers of the product. Although results from this study showed that fruits could be used in masking the "beany flavor" of soybeans thus promoting acceptability of soymilk, further studies on the mechanisms involved are thus recommended to substantiate this claim. More detailed studies to improve the shelf life and marketability of the accepted blend is also necessary so as to further explore this novel blend's applications (Baruwa, 2013).

Table 1: Organoleptic (sensory) mean scores of pineapple soy blend drink "Pina soy"

\begin{tabular}{|l|l|l|l|l|l|}
\hline Pineapple soy blend & Taste & Aroma & Thickness & Color & Overall acceptability \\
\hline $100 \%$ soy & $2.25^{\mathrm{d}}$ & $3.00^{\mathrm{c}}$ & $3.00^{\mathrm{c}}$ & $3.75^{\mathrm{bc}}$ & $2.65^{\mathrm{a}}$ \\
\hline $100 \%$ pineapple & $4.50^{\mathrm{a}}$ & $4.15^{\mathrm{a}}$ & $4.05^{\mathrm{ab}}$ & $4.45^{\mathrm{a}}$ & $4.40^{\mathrm{d}}$ \\
\hline $80 \%$ pineapple $+20 \%$ soy & $4.45^{\mathrm{a}}$ & $4.00^{\mathrm{a}}$ & $4.25^{\mathrm{a}}$ & $4.35^{\mathrm{a}}$ & $4.35^{\mathrm{cd}}$ \\
$60 \%$ pineapple $+40 \%$ soy & $3.70^{\mathrm{b}}$ & $3.60^{\mathrm{b}}$ & $3.70^{\mathrm{bc}}$ & $3.90^{\mathrm{b}}$ & $3.75^{\mathrm{bc}}$ \\
$50 \%$ pineapple $+50 \%$ soy & $3.20^{\mathrm{bc}}$ & $3.45^{\mathrm{bc}}$ & $3.45^{\mathrm{bc}}$ & $3.30^{\mathrm{c}}$ & $3.25^{\mathrm{b}}$ \\
\hline $40 \%$ pineapple $+60 \%$ soy & $2.80^{\mathrm{cd}}$ & $3.20^{\mathrm{c}}$ & $3.25^{\mathrm{c}}$ & $3.50^{\mathrm{bc}}$ & $3.00^{\mathrm{ab}}$ \\
\hline $20 \%$ pineapple $+80 \%$ soy & $2.45^{\mathrm{d}}$ & $2.95^{\mathrm{c}}$ & $3.00^{\mathrm{c}}$ & $3.45^{\mathrm{c}}$ & $2.50^{\mathrm{a}}$ \\
\hline
\end{tabular}



$(\mathrm{p}<0.05)$

Note: means within same column and superscripted with different alphabets are different significantly

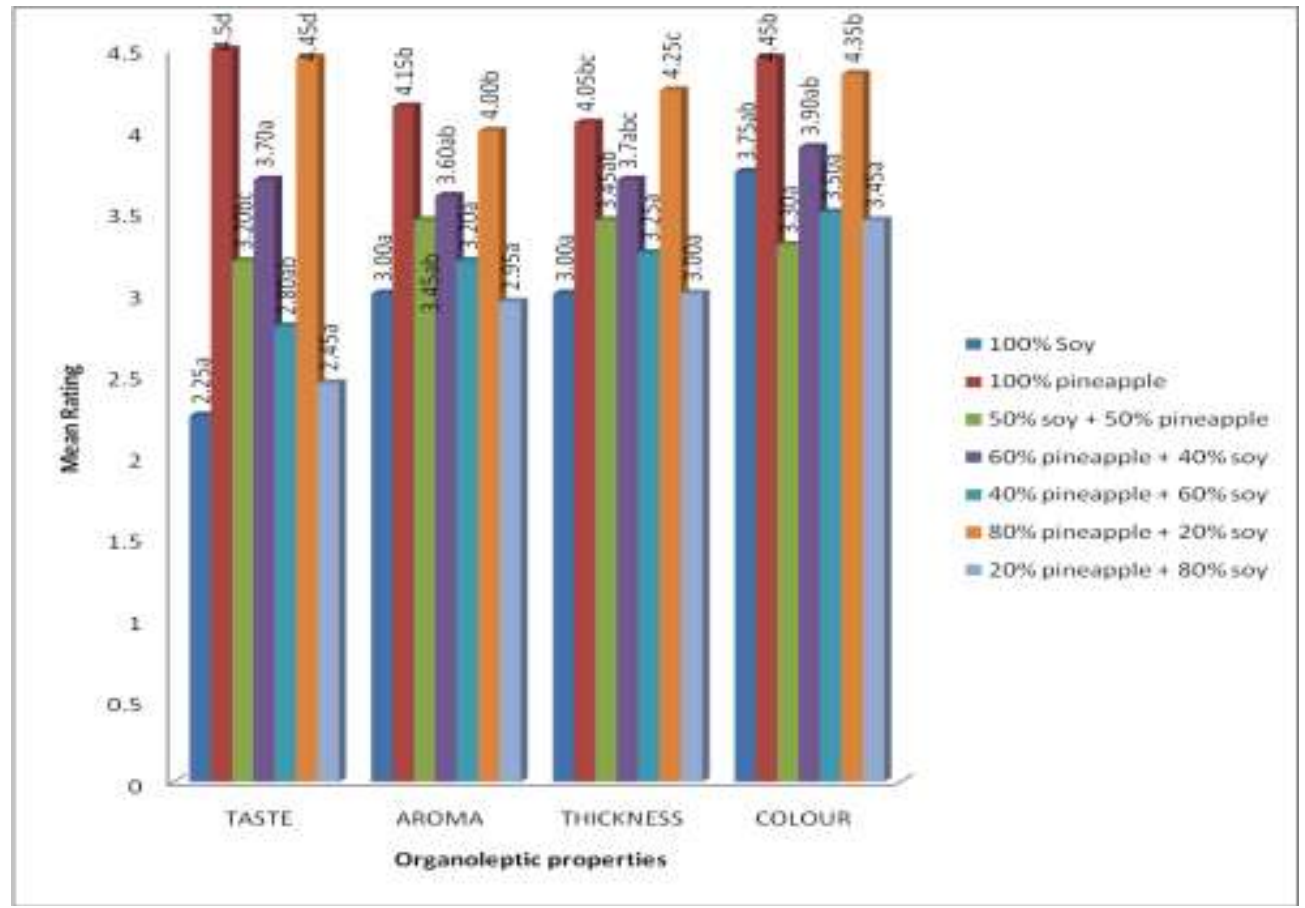

Fig 3: The mean scores for the different combination of Pineapple soy blend drink (Pina soy) Note: mean scores with the same alphabets across bar are not significantly different $(\mathrm{p}>0.05)$

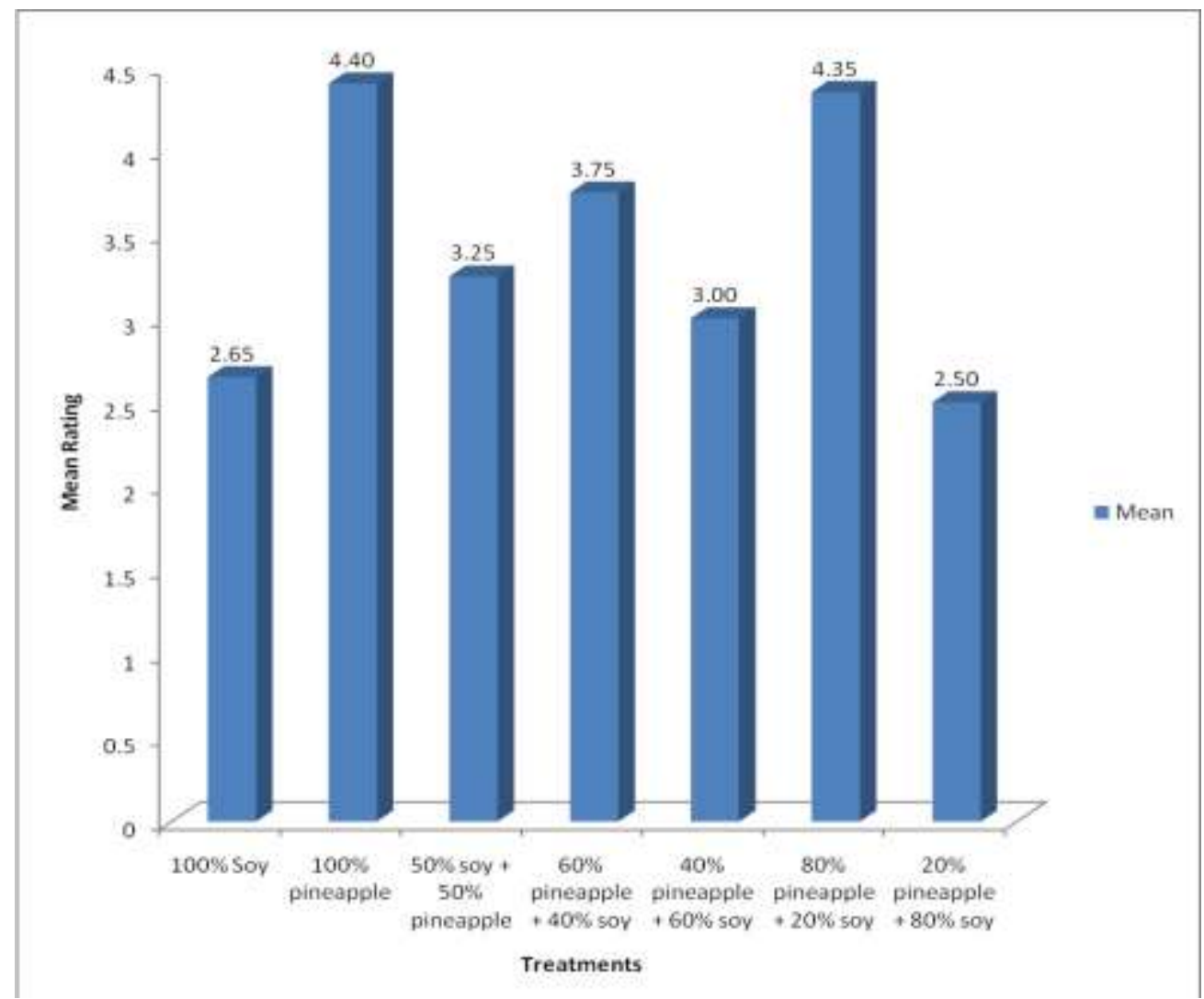

Fig 4: The mean scores for the general acceptability of the pineapple soy blend drink "Pina soy"

\section{Conclusion And Recommendation}

This study has shown that 80/20\% pineapple/soy blend was the most acceptable for "Pina soy" drink, followed by $60 / 40 \%$ pineapple/soy blend. Pineapple may be used in masking undesirable properties in foods and fruit 
juices. Further research should be carried out to determine the acceptability of "Pina soy" with the panelists comprising of older people as the result from this study were obtained from panelist made up of young people.

\section{References}

[1]. Akinosun, F.F. (2010). Production and quality evaluation of juice from blend of water melon and pineapple fruits. J. Food Sci. 2 (4): 54-58.

[2]. Akubor, P.I., Achi, O.K. and Offonry, S.U. 2002. Influence of storage on chemical, microbial and consumer acceptability of a milk-like product made from melon seeds. Plant Foods Human Nutr. 57:191-196.

[3]. Bartolome A. P., Ruperez and C Fuster, 1995. Pineapple fruit; Morphological characteristics, chemical composition and sensory analysis of red Spanish and composition and sensory analysis of red Spanish and smooth cayenne cultivars. Food Chem. 53:75- 79

[4]. Baruwa, O.I. 2013. Profitability and constraints of pineapple production in Osun State, Nigeria. J. Hort. Res. 21(2): 59 - 64

[5]. Boles, J.A. and Pegg, R. 2005. Meat colour. Montana State University and Saskatchewan food product innovation programme, University of Saskatchewan.

[6]. Buono, M.A., Setser, C., Erickson, L.E., Fung, D.Y.C. 1990. Soymilk yoghurt: Sensory evaluation and chemical measurement. J. Food Sci.; 55: 528-531.

[7]. Crepaldi, L. 2006. A influência das cores na decisão de compra: Um estudo do comportamento do consumidor no ABC paulista. In: CONGRESSO BRASILEIRO DE CIÊNCIAS DA COMUNICAÇÃO - INTERCOM, 29, Brasília. Anais... Brasília, p. 1-11.

[8]. De Carvalho, L.M.J., I.M De Castro and C.A.B da silva, 2008. A study of retention of sugars in the process of clarification of pineapple juice by micro and ultra filtration. J. Food Eng. 87: 447- 454

[9]. Dias, N.A.A., Lara, S.B., Miranda, L.S., Pires, I.S.C., Pires, C.V. and Halboth, N.V. 2012. Influence of colour on acceptance and identification of flavor of foods by adults. Universidade Federal dos Vales do Jequitinhonha e Mucuri - UFVJM, Rua da Glória, 187, Centro, CEP 39100-000, Diamantina, MG, Brasil

[10]. Hazen $\quad$ C. 2007. Optimizing soy/dairy blends. Available at [http//www.foodproductdesign.com/articles/463/77h911575356044.html]. Accessed on September 10, 2015

[11]. Igene J.O. and Ebabhamiegbebho, P.A 2009. A manual on the manufacture of jam, jelly and soymilk. Jostraig Publishing Nig Ltd. pp 21- 23.

[12]. Kale, R.V.1., Pandhare, G.R., Satwase A.N and Goswami, D. 2012. Effect of Different Concentration of Orange Juice on Quality Characteristics of Soya Milk Blended Beverage. Food Proc. Technol. 3:2. Available at:http://dx.doi.org/10.4172/21577110.1000140

[13]. Mbajiuka C.S, Obeagu, E.I. Ifediora A.C. and Uzoma, U.G. 2014. Isolation and Identification Of Microorganisms Involved In The Spoilage Of Soymilk. IOSR J. Pharm. Biol. Sci. 9: 29-36.

[14]. Messina, M. J. 1999. Legumes and soybeans: overview of their nutritional profiles and health effects. Am J Clin Nutr, 70: 439S$450 \mathrm{~S}$.

[15]. Messina, M. 2010. A brief historical overview of the past two decades of soy and isoflavone research. J. Nutr, 140:1350S-4S.

[16]. Mollet, B., and Rowland, I. 2002. Functional foods: at the frontier between food and pharmacy. Curr. Opinion Biotechnol, 13:483485.

[17]. Onuekwe, M.E. 2012. Chemical composition of some lesser-known wild fruits and vegetables consumed in Amelum local government area od Anambra State. A Masters thesis submitted to the University of Nigeria, Nsukka. 80p.

[18]. Osundahunsi O.F., Amosu D. and Ifesan B.O.T. 2007, Quality evaluation and acceptability of Soy-yoghurt with different colors and fruit flavours. Am. J. Food Technol. 2: 273-280

[19]. Rapisarada P.T., Anthonio, L.C. and Rosella, A. 1999. Antioxidant Effectiveness as influenced by Phenolic content of Fresh Orange Juice. J. Agric. and Food Chem.; 47: 4718 - 4723

[20]. Rostango, M.A., Palma M, and Barroso C.G. 2007 Ultrasound-assisted extraction of isoflavones from soy beverages blended with fruit juices. Analytica Chimica Acta 597: 265-272.

[21]. Villegas B, Carbonell I and Costell E. 2009. Acceptability of Milk and Soymilk vanilla Beverages. Demographics Consumption Frequency and Sensory Aspects. Food Sci. Technol. Int., 15, 203-210.

[22]. William, S.M. and Akiko, A.S. 2000. Tofu and soymilk production. 3rd ed. Laffegette, California, p. 76.

[23]. Zhou, J. R. 2004. Soy and the prevention of lifestyle-related diseases. Clin Exp Pharmacol Physiol. 31 Suppl 2, S14-9. 